\title{
Transcriptome Alterations in Liver Metastases of Colorectal Cancer After Acquired Resistance to Cetuximab
}

\author{
ZONGCHENG LI $I^{1,2^{*}}$, YULING CHEN $^{3 *}$, WU REN ${ }^{1,4}$, SHUOFENG HU ${ }^{1}$, ZHAOLI TAN $^{3}$, YAN WANG ${ }^{3}$, \\ YAOWEN CHEN $^{1,5}$, JIAN ZHANG ${ }^{1}$, JIAQI WU ${ }^{1}$, TINGTING LI ${ }^{6,7}$, JIANMING XU ${ }^{3}$ and XIAOMIN YING ${ }^{1}$ \\ ${ }^{1}$ Center for Computational Biology, Beijing Institute of Basic Medical Sciences, Beijing, P.R. China; \\ ${ }^{2}$ State Key Laboratory of Proteomics, Translational Medicine Center of Stem Cells, 307-Ivy Translational Medicine \\ Center, Laboratory of Oncology, Affiliated Hospital, Academy of Military Medical Sciences, Beijing, P.R. China; \\ ${ }^{3}$ Department of GI Oncology, 307 Hospital of PLA, Academy of Military Medical Sciences, Beijing, P.R. China; \\ ${ }^{4}$ Department of Obstetrics and Gynecology, Tongji Hospital, Tongji Medical College, \\ Huazhong University of Science and Technology, Wuhan, P.R. China; \\ ${ }^{5}$ Department of Obstetrics and Gynecology, \\ Fuzhou General Hospital of Nanjing Military Command, Fuzhou, P.R. China; \\ ${ }^{6}$ Department of Geriatric Gastroenterology, \\ Chinese People's Liberation Army General Hospital, Beijing, P.R. China; \\ ${ }^{7}$ State Key Laboratory of Kidney Diseases, Chinese People's Liberation Army General Hospital, Beijing, P.R. China
}

\begin{abstract}
Background/Aim: Cetuximab in combination with chemotherapy is recommended as first-line therapy for metastatic colorectal cancer $(m C R C)$ with wild-type RAS. However, drug resistance to cetuximab exists widely in $m C R C$ and reduces the prognosis of patients. Although some genomic alterations have been demonstrated to drive acquired resistance to cetuximab, the overall compendium of inherent molecular mechanisms is still incomplete. Materials and Methods: Four liver metastasis biopsies were collected from two mCRC patients who were treated with cetuximab in combination with 5-fluororacil plus leucovorin and oxaliplatin (FOLFOX) regimen. Results: Transcriptomic analysis revealed global gene expression alterations between paired samples prior to treatment and after acquired resistance. Further bioinformatics analysis discovered differentially expressed
\end{abstract}

This article is freely accessible online.

*These Authors contributed equally to this work.

Correspondence to: Xiaomin Ying, Ph.D., Center of Computational Biology, Beijing Institute of Basic Medical Sciences, Beijing 100850, P.R. China. Tel: +86 1068213039, e-mail: yingxmbio@foxmail.com; yingxm@bmi.ac.cn; Jianming Xu, MD, Department of GI Oncology, 307 Hospital of PLA, Academy of Military Medical Sciences, Beijing 100071, P.R. China. Tel: +86 1051128358, e-mail: jmxu2003@ yahoo.com

Key Words: Acquired resistance, cetuximab, colorectal cancer, transcriptome alteration, regulatory networks. protein-coding genes/lncRNAs/miRNAs, potential miRNA$m R N A$ regulatory networks and IncRNA-mRNA competing endogenous RNA network, which may be potential biomarkers or play roles during the process of acquired resistance to cetuximab. Conclusion: Our study contributes to deciphering the molecular mechanisms of acquired resistance to cetuximab.

Colorectal carcinoma (CRC) is one of the most common cancers and has the third leading incidence rate worldwide. About 1.2 million people are newly diagnosed with colorectal cancer per year (1). Distant metastasis is the main reason for death in CRC patients. About $25 \%$ of CRC patients have distant metastasis at first diagnosis, and $50 \%$ of stage I to stage III patients will eventually develop metastasis (2). Liver is the main target organ of metastasis in colorectal cancer (mCRC), and the majority of CRC patients with liver metastases are unable to get radical resection. For these patients, the main purpose of treatment is to prolong survival, prevent further tumor progression, reduce tumor-related symptoms and improve quality of life (2).

In recent years, the application of chemotherapy and molecular targeted therapies, including anti-epidermal growth factor receptor (EGFR) monoclonal antibodies and anti-vascular endothelial growth factor (VEGF) monoclonal antibodies, has improved the prognosis of mCRC patients. The National Cancer Institute lists 24 drugs for the treatment of mCRC (see list in http://www.cancer.gov/about-cancer/ treatment/drugs/colorectal), among which cetuximab is one of the most effective monoclonal antibodies targeting EGFR on the cell membrane (3) and can significantly improve the 
prognosis of mCRC patients with wild-type RAS (4-9). Cetuximab in combination with chemotherapy has been recommended as first-line therapy (10).

However, drug resistance to cetuximab exists widely. Clinical studies show that cetuximab alone is effective for only about $10 \%$ of mCRC patients (7). Many efforts have been made to find biomarkers or drivers of drug resistance to cetuximab, in order to increase the effectiveness of cetuximab and improve the treatment of mCRC. Drug resistance to cetuximab can be classified into primary and secondary resistance (i.e. acquired resistance). The main causes of primary drug resistance are mutations in codons 12 and 13 at the exon 2 of the KRAS gene $(6,11-13)$, which has been used for routine testing and guiding the clinical treatment $(8,10)$. Moreover, several other genomic alteration events, including mutations in KRAS exons 3 and 4,NRAS exon 2, 3 and 4, $B R A F$ V600E, PIK3CA and HER2 amplification, have also been reported to be associated with primary drug resistance to cetuximab (14-18). Acquired resistance to cetuximab often occurs at 3 to 12 months after effective response to treatment (7). Mutations in KRAS and NRAS genes are the most common causes for acquired resistance to cetuximab $(19,20)$. The amplification of HER 2 and MET genes, the other two members of the receptor tyrosine kinases (RTK), can also lead to acquired resistance by activating downstream RAFMEK-ERK signaling pathway $(21,22)$. In addition, the S492R mutation in the extracellular domain of EGFR can also result in acquired resistance by hindering antibodies from binding to EGFR (23).

Although some genomic alterations have been identified and demonstrated to drive acquired resistance to cetuximab, the overall compendium of inherent molecular mechanisms is still incomplete. Transcriptomic analysis can provide comprehensive insights into molecular mechanisms, which include differential expression analysis and pathway/ regulation networks of protein-coding genes, long noncoding RNAs (lncRNA) and miRNAs. However, transcriptome alterations, especially alterations between matched biopsies prior to treatment and after acquired resistance, are largely unknown up to date.

In this study, we collected four liver metastasis biopsies from two mCRC patients who were treated with cetuximab in combination with 5-fluororacil plus leucovorin and oxaliplatin (FOLFOX). Each patient had undergone ultrasound-guided biopsies prior to treatment and after acquired resistance (tumor re-progression after effective response to treatment for more than six months). High-throughput transcriptome sequencing, including RNA-Seq and small RNA-Seq, were conducted for all the four samples. Transcriptomic analysis revealed gene expression alterations between paired samples prior to treatment and after acquired resistance. Further bioinformatics analysis discovered differentially expressed protein-coding genes/lncRNAs/miRNAs, potential miRNA-mRNA regulatory networks and lncRNA-mRNA competing endogenous RNA (ceRNA) network, which may be potential biomarkers or play roles during the process of acquired resistance to cetuximab. Our study may contribute to deciphering the molecular mechanisms of acquired resistance to cetuximab.

\section{Materials and Methods}

Patient inclusion and sample collection. A retrospective single-center study was performed at the 307 Hospital, Academy of Military Medical Sciences, Beijing, China. Eligible patients had pathologically confirmed metastatic colorectal cancer (mCRC) harboring wild-type $K R A S$ codons 12 and 13 and $B R A F$ codon 600 determined via Sanger sequencing of the tumor tissue DNA, and they received targeted therapy and chemotherapy for the first time. Patients received cetuximab in combination with FOLOX chemotherapy. Computed tomography (CT) scans were performed and reviewed every 4 to 6 weeks to evaluate clinical response using the Response Evaluation Criteria in Solid Tumors (RECIST), version 1.1 (24). All the patients signed an informed consent for liver biopsy and publication of the results. Fresh tumor tissues from metastatic liver lesions were obtained at baseline and disease progression. Tumor biopsies were frozen at liquid nitrogen immediately when taken out and were linked to demographic, clinical and genetic data stored in a secure research database. This study protocol was approved by the local ethics committee (KY-2011-8-3). Tissue acquisition and handling of human tissue specimens were carried out in accordance with the institutional and state regulations.

Treatment of cetuximab in combination with chemotherapy. All of these agents were administered intravenous (IV) via an ambulatory pump and a central venous line. Treatment was continued until disease progression. Cetuximab: $400 \mathrm{mg} / \mathrm{m}^{2} \mathrm{IV}$ over $2 \mathrm{~h}$ at the first week as an initial dose, then $250 \mathrm{mg} / \mathrm{m}^{2}$ IV over $1 \mathrm{~h}$ weekly. FOLFOX regimen: Oxaliplatin $85 \mathrm{mg} / \mathrm{m}^{2}$, IV over $2 \mathrm{~h}$, day 1 ; Leucovorin $400 \mathrm{mg} / \mathrm{m}^{2}$, IV over $2 \mathrm{~h}$, day $1 ; 5$-fluorouracil $400 \mathrm{mg} / \mathrm{m}^{2}$, bolus on day 1 , then $2,400 \mathrm{mg} / \mathrm{m}^{2} \mathrm{IV}$ infusion over $46 \mathrm{~h}$.

Liver biopsy and pathology assessment. Ultrasound guided liver biopsies were performed using a 18 gauge biopsy needle, 2 cores with a minimum length greater than $5 \mathrm{~mm}$ were taken, and each of the cores were mirror sectioned, half of which were send to pathology department for H\&E staining and pathological evaluation to ensure the tumor content was more than $50 \%$. The rest of the tissue was placed in a freezing tube with RNAlater, frozen at $-80^{\circ} \mathrm{C}$.

RNA isolation, library construction and RNA sequencing. Total RNA was isolated from fresh frozen tumor tissues using Trizol reagent. Library constructions of Poly-A mRNA and small RNA were conducted using TruSeq Stranded mRNA Library Prep Kit (Illumina, San Diego, CA, USA) and TruSeq Small RNA Library Preparation Kits (Illumina, USA). The high-throughput sequencing was carried out using Illumina Hiseq 2000.

Mapping and quantification. For mRNA sequencing data, poor quality reads were filtered from the raw paired-end reads using custom perl script. Then the paired-end reads were aligned to the hg19 human genome assembly using Tophat program version 2.0.13 (25). The resulting alignments were saved as a BAM file. The raw 


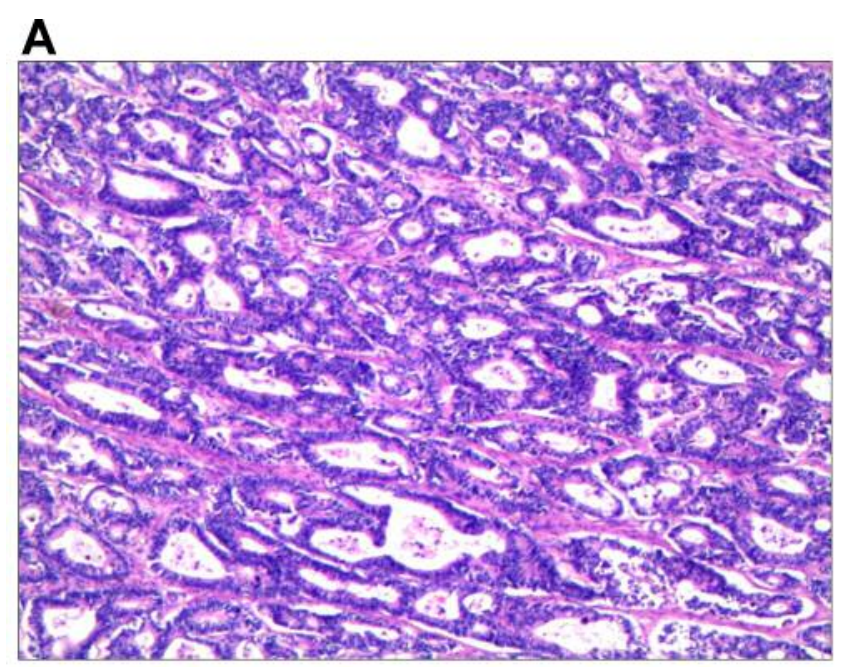

Primary tumor of colon

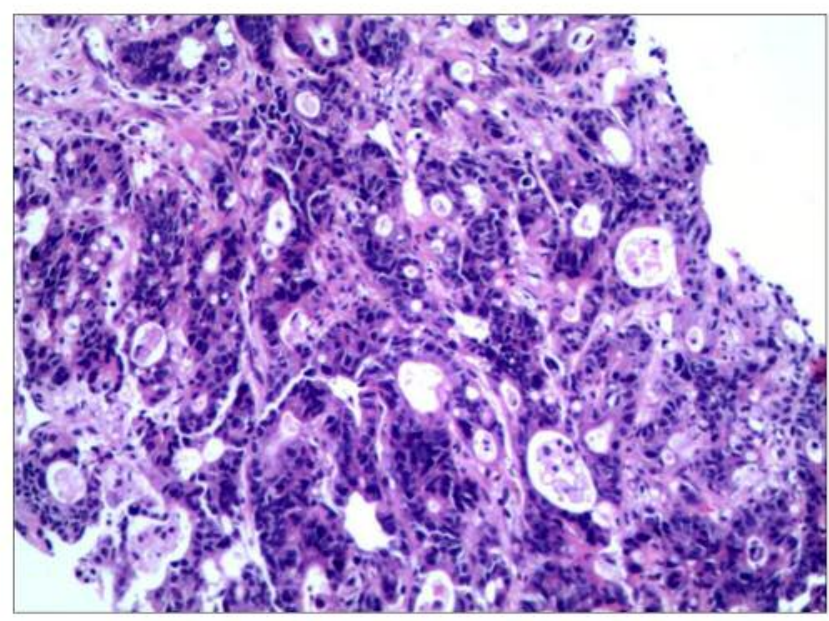

Liver metastasis

B

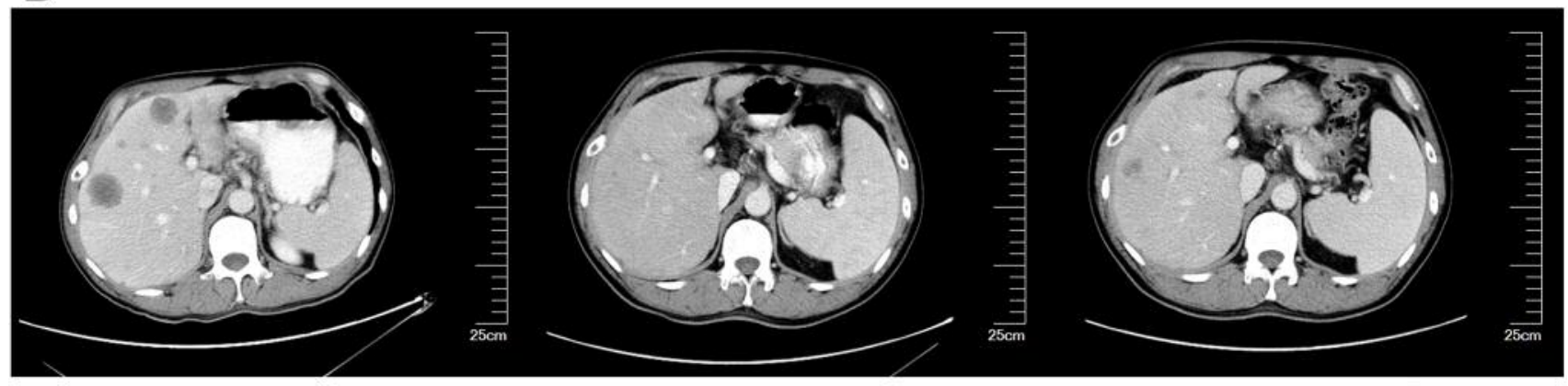

Base line (2012-10-6)

Best response at 24th weeks (2013-3-22) Progression disease at 32th weeks (2013-5-16)

Figure 1. Pathological sections and CT scans of liver lesions. (A) H\&E staining picture of primary tumor of colon (left) and liver metastasis (right). (B) Tumor response to cetuximab containing therapy in patient $m C R C 002$ with liver metastases. CT scan revealed multiple heterogeneously enhancing tumor masses in the right and left lobes of liver, after 2 cycles ( 8 weeks) of chemotherapy plus Cetuximab, dramatic tumor regression at all sites of disease were seen, the regression lasted 24 weeks. After continued therapy for more than 7 months, the patient developed disease progression.

counts for each gene were calculated using the HTSeq-count script (26) by counting the number of reads overlapping with genes (mRNAs and lncRNAs) annotated in GENCODE version 15 (27). For small RNA sequencing data, after removing adaptors and poor quality reads, small RNA reads were aligned to know human miRNAs from miRBase v21 (28). The raw count for each miRNA was calculated. The workflow is illustrated in Supplementary Figure 1.

Estimation of tumor purity. Tumor purity of the four samples was estimated using the ESTIMATE R package (29). ESTIMATE method uses gene expression profiles of 141 immune genes and 141 stromal genes to obtain ESTIMATE scores and purity was estimated using the formula described in Yoshihara et al. (29).

Categories and subcellular localization of protein-coding genes. Significantly up-regulated genes after acquired resistance were assigned to different categories and subcellular localizations according to Uniprot database (30).
Literature search. The combination of gene name and any of these keywords, including "cancer", "tumor", "resistant", "resistance", "anti-drug" and "drug-resistance", were used in PubMed literature search. According to the results of the literature search, differentially expressed genes were manually classified into five groups, which are tumor-related genes ("cancer" and "tumor"), drug resistancerelated genes ("resistant", "resistance", "anti-drug" and "drugresistance"), drug resistance genes ("resistant", "resistance", "antidrug" and "drug-resistance"), tumor suppressor genes ("cancer" and "tumor") and other genes.

Construction of miRNA-mRNA negative regulatory network and ceRNA network. miRwalk (31), at default settings, was used to predict target mRNAs for each differentially expressed miRNA. The potential target mRNAs, which were supported by at least three prediction methods of miRwalk, RNA22, miRANDA and Targetscan and differentially expressed in opposite direction of the miRNA, were retained. Then, these potential regulatory links between 
miRNAs and mRNAs with significant opposite expression were used for construction of a miRNA-mRNA negative regulatory network.

Based on gene annotations of GENCODE v15 (27), we selected lncRNAs with the given "gene_type", including lincRNA, antisense RNA, sense intronic, overlap sense and processed_transcript. The ceRNA prediction procedure includes four steps (Supplementary Figure 2): i) predicting the lncRNAmiRNA interactions based on the CLIP-Seq data from Starbase database (Version 2.0) for differentially expressed lncRNA; ii) obtaining experiment validated miRNA-mRNA pairs based on the miRtarbase database for differentially expressed mRNAs; iii) generating potential lncRNA-mRNA relationships connected by miRNAs; iv) excluding lncRNA-mRNA pairs which showed expression changes in different directions. Cytoscape was employed for visualization of networks.

Availability of data and material. Raw data and gene expression profiles for this study are accessible via the GEO repository (http://www.ncbi.nlm.nih.gov/geo/) under accession identification number GSE84270. Supplementary tables and supplementary figures can be downloaded from http://www.omicsnet.org/pub/ coloncancer.html.

Statistical analysis. For gene or miRNA differential expression analysis, paired sample design was employed using $\mathrm{R}$ package DESeq2 version 1.8.0 (32), which was a powerful method for the detection of differentially expressed genes of count data from RNASeq using shrinkage estimation for dispersions and fold changes to improve stability and interpretability of estimates. Fold change $>1.5$ and FDR $<0.05$ was adopted as a statistically significant threshold. The variance Stabilizing Transformation function was used to normalize the count data for visualization.

\section{Results}

Clinical and treatment information of patients. Two patients who were newly diagnosed and pathologically confirmed with metastatic colorectal cancer (mCRC) harboring wildtype $K R A S$ codons 12 and 13 and $B R A F$ codon 600 were screened for eligibility between August 2011 and December 2013. They were treated with cetuximab in combination with FOLFOX regimen (see Materials and Methods) and obtained continuous partial responses for more than six months. CT scans of liver lesions were performed every four to six weeks. The scans at baseline, best response and disease progression are shown in Figure 1. Detailed clinical and treatment information were provided in Supplementary Table I.

Transcriptome expression profiles of four mCRC biopsies. The four biopsy samples were evaluated by two pathologists and tumor purities were confirmed to be greater than $50 \%$. Each biopsy sample was subjected to high-throughput RNA and small RNA sequencing to obtain expression profiles of genes (protein-coding genes and lncRNAs) and miRNAs. We evaluated the tumor purity scores using ESTIMATE algorithm (29) and gene expression profiles. The tumor purity scores of the four samples ranged from 0.79 to 0.92
(Supplementary Table II), ensuring the reliability of the analysis results. Next, we compared gene and miRNA expression levels between paired samples of prior treatment and after acquired resistance for each patient (Figure 2). The results showed that many genes (Figure $2 \mathrm{~A}$ and $\mathrm{B}$ ) and a few miRNAs (Figure 2C and D) were significantly up- or downregulated in the two patients after drug resistance occurred.

Differentially expressed protein-coding genes after acquired resistance to cetuximab. We identified 782 protein-coding genes differentially expressed between biopsy samples of prior treatment and after acquired resistance. Among them, 699 genes were up-regulated in the biopsy samples after acquired resistance and 83 genes were down-regulated (Figure 3A, Supplementary Table III). The up-regulated gene number is eight times greater than that of the down-regulated genes. Moreover, the change folds of up-regulated genes are much greater than those of the down-regulated genes $(11.17 \pm 0.64$ vs. 5.23 $\pm 0.29, p<0.001$, Mann-Whitney $U$-test). Specifically, 282 genes were up-regulated by $>10$ fold and an adjusted $p$ value $<0.01$, covering $40.3 \%$ (282/699) of all the up-regulated genes, whereas only 5 genes were down-regulated by $>10$ fold and adjusted $\mathrm{p}$ value $<0.01$, covering $6.0 \%$ of all the downregulated genes. These data show that many more genes were activated than repressed when resistance occurred.

GO annotation and KEGG pathway enrichment analysis was then performed on 699 significantly up-regulated genes and 83 down-regulated genes using DAVID webserver (33, 34), respectively. The top five up-regulated biological processes were: small molecule metabolic process, oxidation-reduction process, xenobiotic metabolic process, regulation of complement activation, and negative regulation of endopeptidase activity. The top five enriched up-regulated KEGG pathways were: complement and coagulation cascades, metabolic pathways, chemical carcinogenesis, glycine, serine and threonine metabolism, and retinol metabolism (Figure 3B). These results showed that metabolism and complement activity are more active after resistance to cetuximab occurred, which is consistent with the previous reports showing that metabolic alterations help cancer cells to proliferate rapidly and develop drug resistance phenotypes $(35,36)$. However, the down-regulated genes had no enriched biological processes or KEGG pathways.

Four keratins, KRT1, KRT14, KRT5 and KRT2, were most significantly up-regulated among all the up-regulated genes (Supplementary Table III). The change folds were all greater than 110, far greater than those of other up-regulated genes. KRT1, KRT2 and KRT5 are type II cytokeratins and KRT14 is a type I cytokeratin. KRT5 and KRT14 are usually expressed in the basal layer of the epidermis and stratified squamous epithelia, and form heterotetramers. KRT5 and KRT14 are diagnostic markers in breast cancer (37), and their high expression indicates aggressive behavior and poor 


\section{A gene expression of mCRC001}

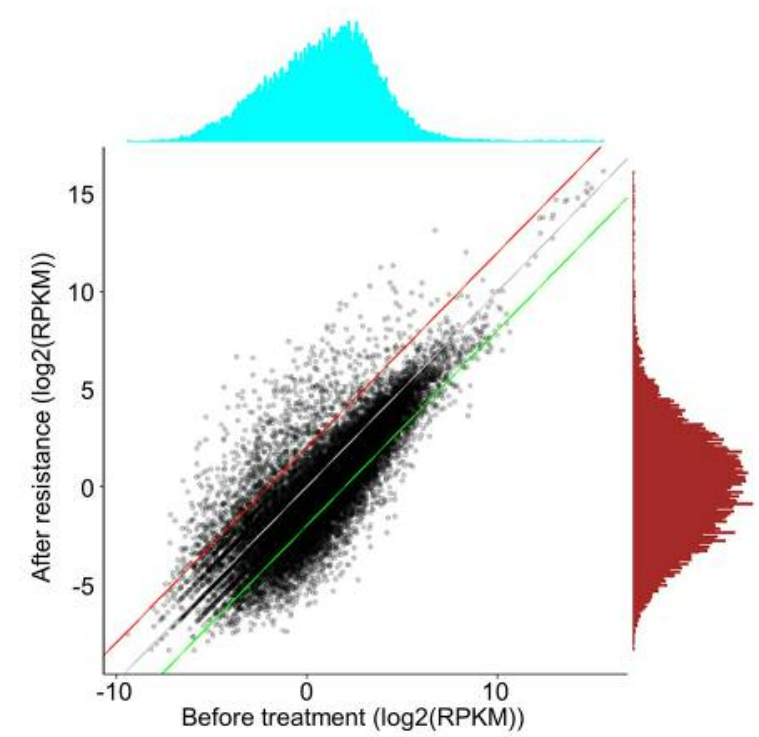

\section{C gene expression of mCRC002}

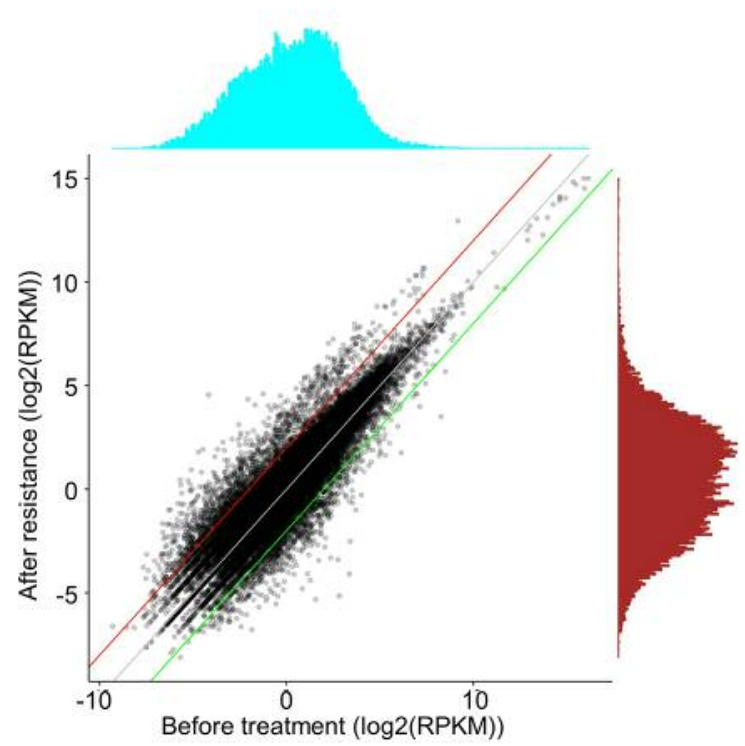

\section{B miRNA expression of $\mathrm{mCRC} 001$}

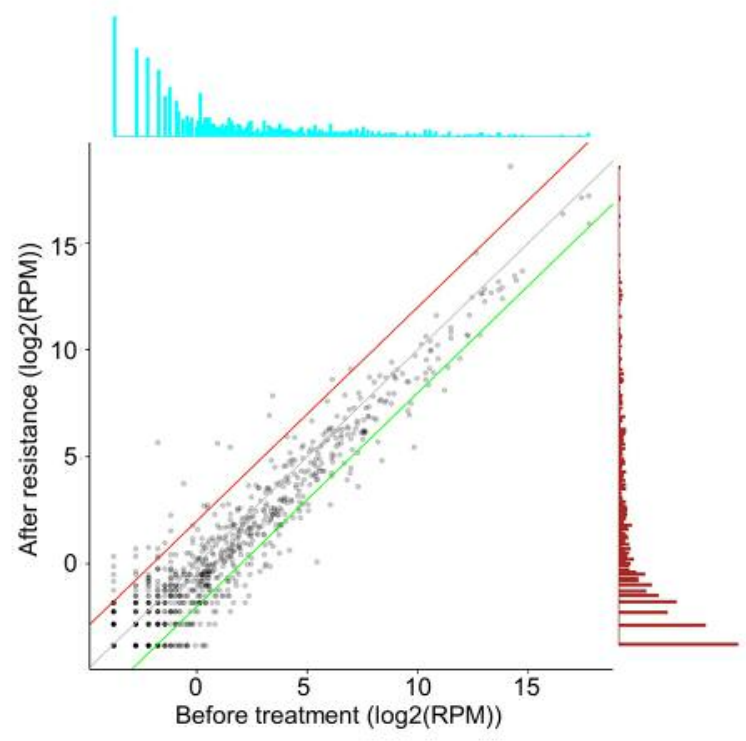

D miRNA expression of $\mathrm{mCRC} 002$

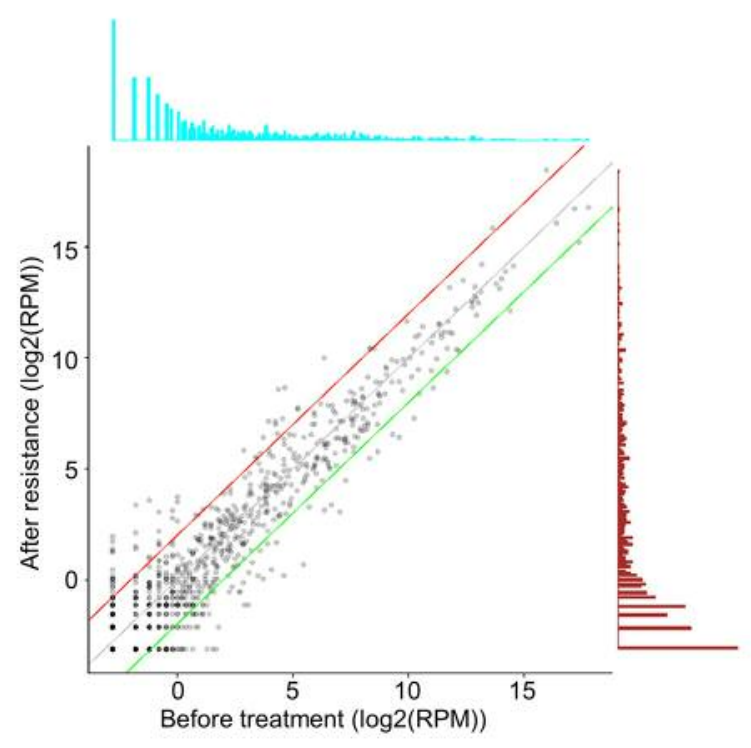

Figure 2. Comparisons of gene and miRNA expression between paired samples of prior treatment and after acquired resistance for each patient. Scatterplots of gene and miRNA expression between paired samples prior to treatment and after acquired resistance for $m C R C 001$ (A for genes and $B$ for miRNAs) and $m C R C 002$ ( $C$ for genes and $D$ for miRNAs). Grey line stands for $y=x$; red line stands for $y=x+2 ;$ green line stands for $y=x-2$. In panel A for example, black points above red line account for genes up-regulated more than twice in the acquired resistance sample, while black points under green line account for genes down-regulated more than twice in the acquired resistance sample. Histograms alongside each scatterplot show distributions of gene and miRNA expression of corresponding samples (cyan is for sample of prior treatment and brown for acquired resistance).

prognosis $(38,39)$. KRT1 is a diagnostic marker in skin squamous cancer (37). Our result suggests that KRT1, KRT2, KRT5 and KRT14 may be markers of resistance to cetuximab in $\mathrm{mCRC}$.
We further inspected the kinases, cytokines and cell surface receptors in the up-regulated genes (Figure 3C), since they can more readily become drug targets. Two nuclear receptors, ESR1 (Estrogen receptor 1) and AR 
(Androgen receptor), were up-regulated after acquired resistance to cetuximab. Six kinases were also up-regulated, including MET, RET, MST1, PDK4, KHK and DAPK1. Eight cell surface receptors were up-regulated, including MET, RET, GHR, IL1R1, IL6R, SMO, GFRA1 and GFRA2. Twelve growth factors and cytokines were up-regulated, including CCL16, CCL19, CCL21, CXCL12, FGF21, GDF2, GREM2, IGF1, IGF2, INHBC, INHBE and NRG1. Among these genes, MET and RET are members of the RTK (Receptor tyrosine kinase) family (40), the same as EGFR which is the target of cetuximab. Amplification of MET gene has been reported to lead to acquired resistance to cetuximab $(21,22)$. RET (41) and ESR1 $(42,43)$ were reported to correlate with endocrine resistance in breast cancer. SMO gene amplification was associated with resistance to EGFR TKIs in human lung cancer (44). NGR1 was reported to provide resistance to MEK inhibitors in metastatic uveal melanoma (45). Our results suggested that these up-regulated kinases, cytokines and cell surface receptors may play roles in acquired resistance to cetuximab and that the inhibitors or drugs targeting these proteins may sensitize CRC to cetuximab treatment.

A literature search was also conducted for all 699 upregulated genes (see Materials and methods). Twenty-one genes have been reported to lead to drug resistance in cancers (Figure 3D, Supplementary Table IV). Fifty-six genes have been shown to correlate with drug resistance, sixty-two genes are known cancer genes and 171 genes have been reported to be associated with cancer (Figure 3D, Supplementary Table III). This result showed that nearly half $(296 / 699=42.3 \%$, Supplementary Table III) of the up-regulated genes are known drug resistance or cancer associated genes. The rest of the genes may also play roles in drug resistance or cancer development and are worth further validation.

Differentially expressed lncRNAs after acquired resistance to Cetuximab. Fifty-three lncRNAs were differentially expressed between biopsies of prior treatment and after acquired resistance (25 up-regulated and 28 down-regulated, Supplementary Table III). The change folds of up-regulated lncRNAs were much greater than those of down-regulated lncRNAs $(10.82 \pm 1.15$ vs. $4.97 \pm 0.32, p<0.001$, MannWhitney $U$-test). The top two significantly up-regulated lncRNA were H19 [fold change $(\mathrm{FC})=16.7$, adjusted $p<0.001]$ and HULC $(\mathrm{FC}=12.5$, adjusted $p<0.001$, Supplementary Table III). Up-regulation of H19 was reported to be associated with drug resistance in human hepatocellular carcinoma cells (46). Up-regulation of HULC was reported to promote the progression of hepatocellular carcinoma (47) and CRC (48). Two down-regulated lncRNAs MALAT1 ( $\mathrm{FC}=3.7$, adjusted $p=0.005$ ) and GAS5 ( $\mathrm{FC}=3.3$, adjusted $p=0.047$, Supplementary Table III) were reported to be associated with drug resistance. Down-regulation of
MALAT1 was observed in vincristine-resistant acute lymphoblastic leukemia (49). Down-regulation of GAS5 leads to trastuzumab resistance in breast cancer (50) and was reported to be associated with cisplatin resistance in nonsmall cell lung cancer (NSCLC) (51). Our results suggest that these differentially expressed lncRNAs may also play roles in resistance to cetuximab in $\mathrm{mCRC}$.

Interestingly, more lncRNAs are down-regulated in acquired resistance samples even though down-regulated genes were significantly less than up-regulated genes $(p<0.001$, one-sided Fisher's Exact Test, Supplementary Table V). This result indicates that high expression of these down-regulated lncRNAs may play important roles in sensitizing CRC to cetuximab treatment.

Potential miRNA regulatory network and competitive endogenous RNAs associated with Cetuximab resistance. Twenty mature miRNAs were significantly up-regulated ( $>3$ folds) and nine mature miRNAs were significantly downregulated ( $>3$ folds) when resistance to cetuximab occurred (Figure 4A, Supplementary Table VI). The 5' and 3' cleavage products (denoted as $-5 \mathrm{p}$ and $-3 \mathrm{p}$ in the names of mature miRNAs) of four miRNA precursors were both up-regulated in biopsies after acquired resistance, including mir-885, mir122, mir-483, and mir-139. (Supplementary Table VI). Interestingly, miR-885-5p was reported to be up-regulated in non-small cell lung cancer cell resistance to gemcitabine (52), and was up-regulated in liver metastasis specimens of CRC patients (53). miR-885-5p was the most up-regulated miRNA in lymphovascular invasion carcinoid tumors compared with tumors without invasion (54). Even more interestingly, miR-885-5p was detected in serum. High serum miR-885-5p expression independently predicted prognosis and metastasis in CRC (55). These results suggest that the significantly up- or down-regulated miRNAs may potentially become biomarkers for cetuximab resistance.

We further built the miRNA-mRNA negative regulatory network among differentially expressed miRNAs and mRNAs (Figure 4B, C, Supplementary Figure 1). Although downregulated miRNAs were much less in number than up-regulated miRNAs (9 vs. 20), the target mRNAs of the down-regulated miRNAs were much more than those of the up-regulated miRNAs (Average target mRNA number: $35.22 \pm 22.16 \mathrm{vs}$. $5.53 \pm 3.45, p=0.004, t$-test $)$. These results suggest that the downregulated miRNAs may play more important roles in resistance to cetuximab in mCRC. Up-regulation of the down-regulated miRNAs might sensitize CRC to cetuximab treatment.

Competitive endogenous RNA (ceRNA) is a pair of RNAs, which have the same miRNA response element (MRE) and may competing for the same endogenous miRNAs, and their expression changes in the same direction $(56,57)$. Based on this assumption, we predicted the ceRNA network among differentially expressed mRNAs and lncRNAs (Figure 4D). 
A

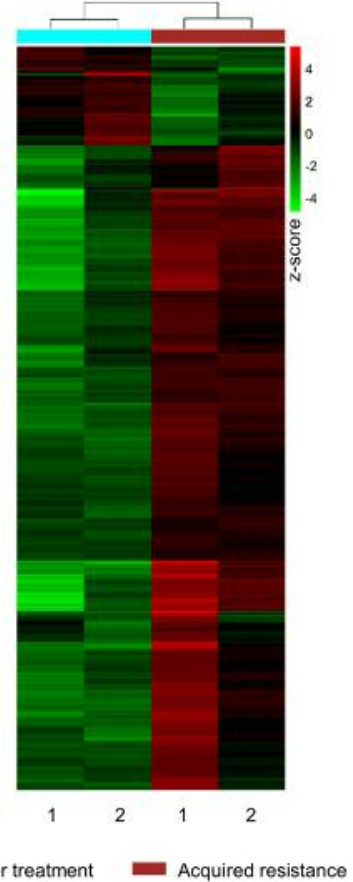

B

\section{GO Biological Processes}

- $\log 10$ (Adjusted $P$ value)

$$
\begin{array}{lllllllllll}
0 & 5 & 10 & 15 & 20 & 25 & 30 & 35 & 40 & 45
\end{array}
$$

small molecule metabolic process oxidation-reduction process xenobiotic metabolic process regulation of complement activation negative regulation of endopeptidase activity
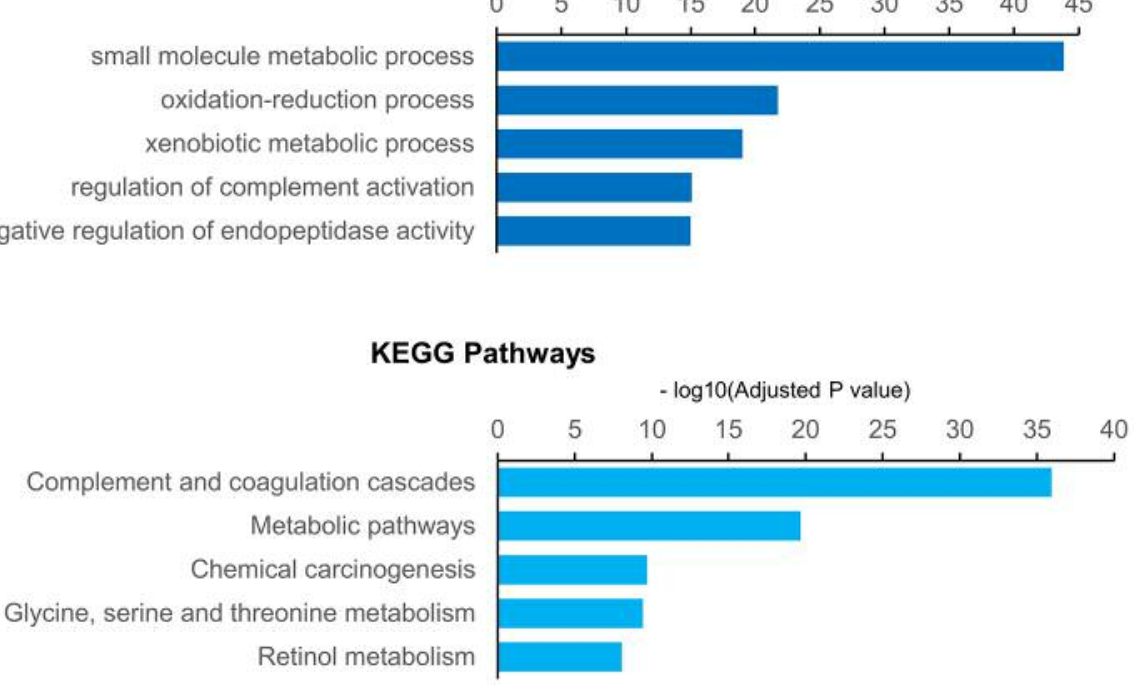

\section{C}

\begin{tabular}{|c||c||c||c||c||c|}
\hline CCL16 & CCL19 & CCL21 & CXCL12 & FGF21 & GDF2 \\
\hline \hline GREM2 & IGF1 & IGF2 & INHBC & INHBE & NRG1 \\
\hline
\end{tabular}

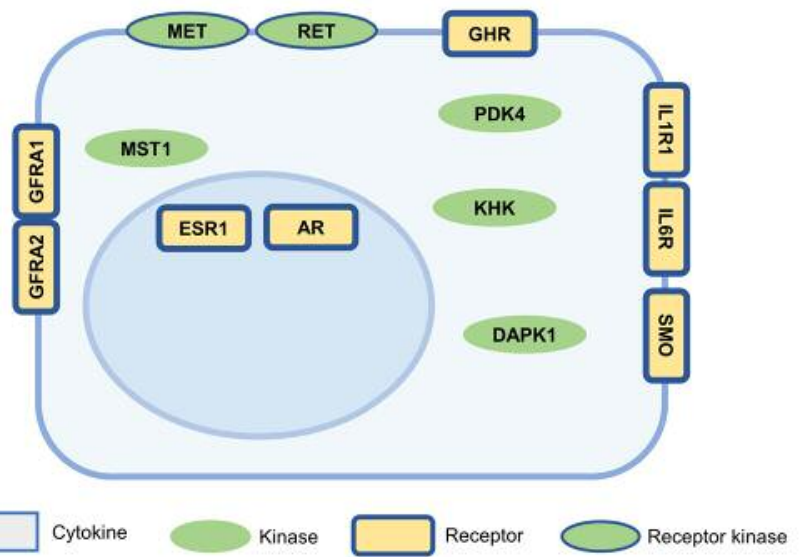

D

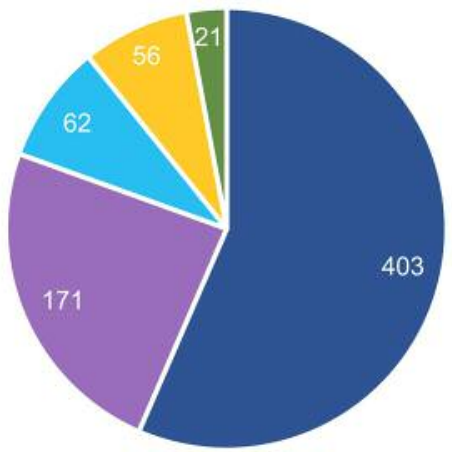

Drug resistance Gene Drug resistance associated Gene

Cancer Gene

Cancer-associated Gene

Other genes

Figure 3. Analysis of differentially expressed genes after acquired resistance to cetuximab. (A) Heatmap of 835 differentially expressed genes between 2 groups prior to treatment and after acquired resistance. $(B)$ The results of the gene functional enrichment analysis of 699 up-regulated proteincoding genes. Top panel shows the top 5 enriched KEGG pathways, and bottom panel shows the top 5 enriched biological processes. (C) Subcellular components and location of 26 specific genes, which code for cytokine, kinase, and cell surface receptors, among up-regulated genes. (D) Pie chart of categories of up-regulated genes identified by literature search.

Seven lncRNAs and 32 mRNAs formed the ceRNA network. H19, the top significantly up-regulated lncRNAs, had the most potentially competitive mRNAs. The other 6 lncRNAs had 1 to 8 potentially competitive mRNAs. Some lncRNAs and mRNAs with known functions in cancer were involved in the network. For example, lncRNA H19, an imprinted gene, plays an important role in mammalian development (58) and has been reported to be related to development, metastasis and drug-resistance of various tumors (59-61). LncRNA Gas5, a tumor suppressor, has been correlated with 
A

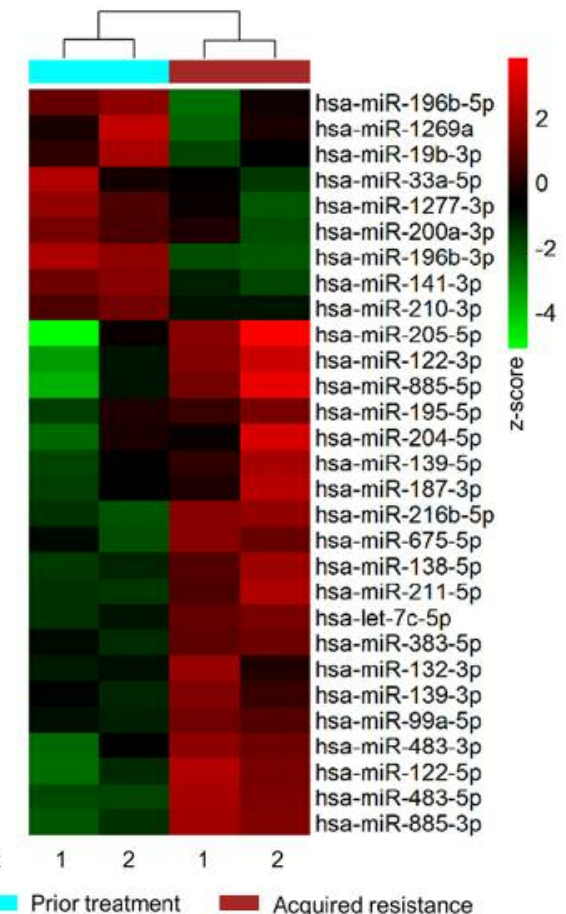

Patient

Prior treatment Acquired resistance

C

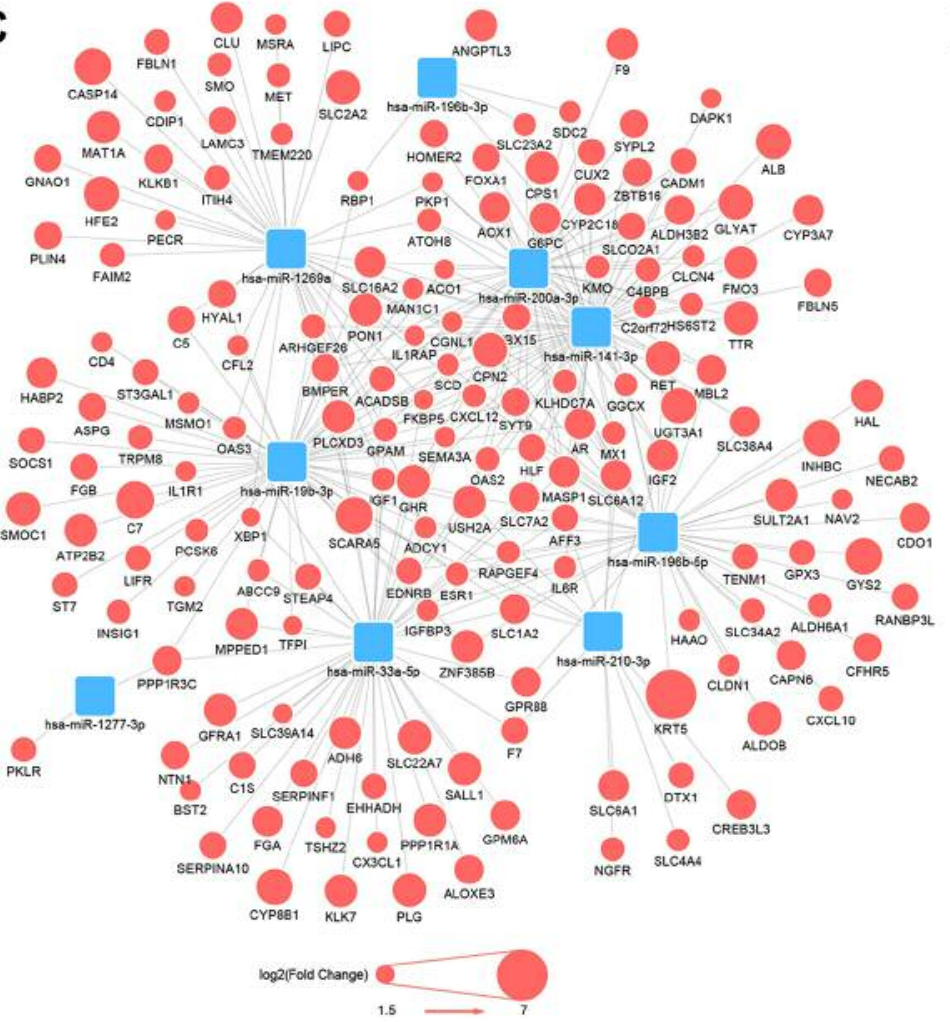

B

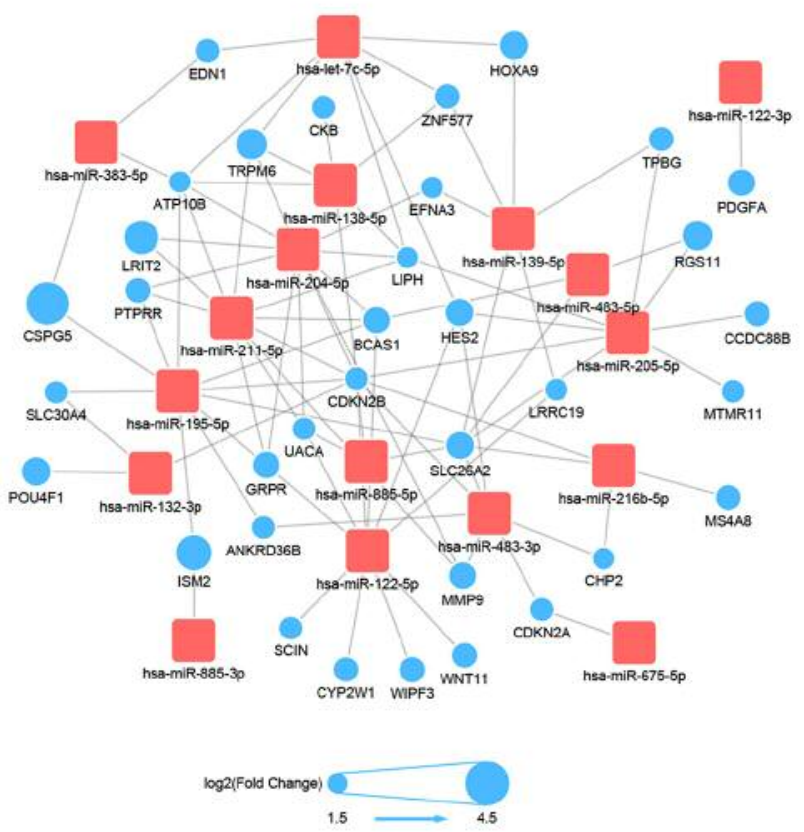

D
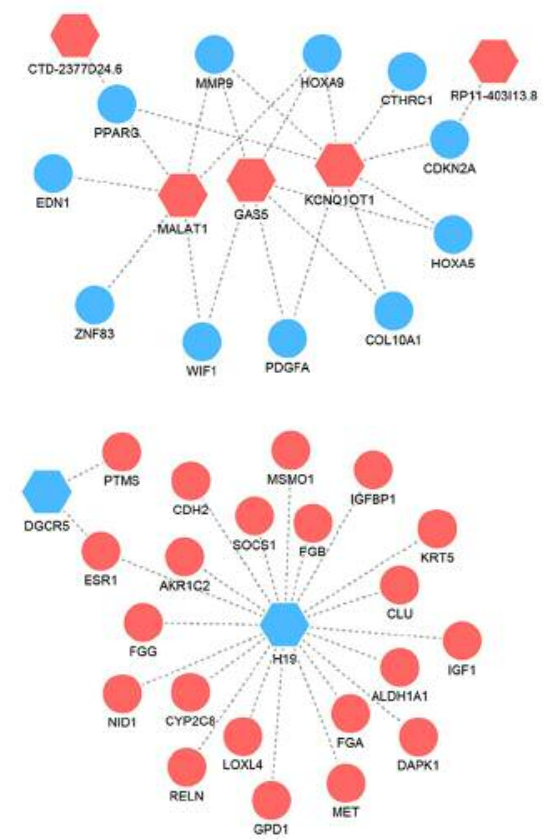

Figure 4. Integrative analysis of differentially expressed miRNAs, mRNAs and lncRNAs identified potential regulatory networks. (A) Heatmap of 29 differentially expressed miRNAs between 2 groups prior to treatment and after acquired resistance. $(B$ and $C$ ) Predicted miRNA-mRNA negative regulatory network among differentially expressed miRNAs and mRNAs. Yellow squares represent up-regulated miRNAs (B) and down-regulated miRNAs (C). Circles represent down-regulated (blue in B) and up-regulated (red in C) mRNAs, and circle sizes are proportional to fold changes. (D) Predicted IncRNA-mRNA ceRNA regulatory network among differentially expressed lncRNAs and mRNAs. Yellow squares represent down-regulated (left panel) and up-regulated lncRNAs (right panel). Circles represent up-regulated (red in left panel) and down-regulated (blue in right panel) $m R N A s$. 
drug resistance $(62,63)$. MMP9, a member of the MMP family, plays an important role in early progression of tumor and may promote proliferation, adhesion, migration and angiogenesis (64-66). CDKN2A (P16) is a known tumor suppressor gene (67-69). WIF1 is known to inhibit the Wnt protein by interacting with Frizzled, and then inhibit Wnt/ $\beta$ catenin signaling transduction (70-72). The competitive relationship between these lncRNAs and mRNAs may exert functions in tumor resistance to cetuximab.

\section{Discussion}

Acquired resistance to cetuximab widely occurs in the clinic. However, since paired biopsies prior to treatment and after acquired resistance from mCRC patients can rarely be obtained, global transcriptome alterations of paired biopsies are still unknown. We obtained four paired biopsy samples from two liver mCRCs, prior treatment with cetuximab and 5-FOLOX and after acquired resistance. By using high-throughput RNA and small RNA sequencing technology, we delineated global transcriptome changes when resistance occurred. Differential expression analysis, miRNA regulatory network and ceRNA network analysis suggested that some protein-coding genes, lncRNAs and miRNAs may be biomarkers and may play roles in the acquired resistance to cetuximab in mCRC. Our results provide clues for further studies of the molecular mechanisms of acquired resistance to cetuximab.

Cetuximab targets EGFR on the cell membrane, which is a member of the RTK family. The mutations or amplifications of several RTK family genes, including $K R A S$, $N R A S, H E R 2$ and $M E T$, have been reported to result in acquired resistance to cetuximab (19-23). In our analysis, another RTK family member, RET, was significantly upregulated in the biopsies of acquired resistance. Furthermore, three miRNAs miR-196b-5p, miR-141-3p and miR-200a-3p predicted to target $R E T$ mRNA were down-regulated in the biopsies of acquired resistance. RET has been reported to be related to drug resistance to endocrine therapy (73). Our results suggest that up-regulation of RET might also cause cetuximab resistance in mCRC.

Twenty-nine miRNAs were significantly up- or downregulated in the biopsies of acquired resistance. MiRNAs are small molecules, $22 \mathrm{nt}$ in length. Some miRNAs can be detected in serum, for example, miR-885-5p. In our analysis, miR-885-5p was up-regulated in acquired resistance samples. It was reported that high serum miR-885-5p expression independently predicted prognosis and metastasis in CRC (55). These results suggest that miR-885-5p might be a serum biomarker of acquired resistance to cetuximab.

The functions and mechanisms of miRNAs and lncRNAs in acquired resistance are largely unknown. By constructing miRNA-mRNA regulatory networks and lncRNA-mRNA ceRNA networks, we predicted potential regulatory mechanisms for miRNAs and lncRNAs. For example, several miRNAs such as miR-141-3p and miR-1269a might contribute to sensitizing CRC to cetuximab treatment by inhibiting the genes that drive acquired resistance. LncRNAs such as H19 and MALAT1 might regulate critical genes that drive or inhibit resistance as competitive endogenous RNAs. This information provides clues for investigating the roles and mechanisms of miRNAs and IncRNAs in resistance to cetuximab.

Taken together, we depicted global transcriptome alterations between paired biopsy samples prior to treatment and after acquired resistance from two liver mCRCs treated with cetuximab and 5-FOLOX. To our knowledge, this is the first transcriptome profiling for paired biopsies of prior treatment and acquired resistance to cetuximab. The conclusion is preliminary due to the small sample size. Nonetheless, our results still provide clues for subsequent studies on the biomarkers and molecular mechanisms of cetuximab resistance.

\section{Conclusion}

Our study contributes to deciphering the molecular mechanisms of acquired resistance to cetuximab.

\section{Conflicts of Interest}

The Authors declare no competing financial interests.

\section{Funding}

This work was supported by National Key R\&D Program of China (Grant No. 2017YFC0908300 to X. Ying), the China National High Technology Research and Development Program (No. 2014AA020604 to X. Ying), the National Natural Science Foundation of China Project (No. 81573458 to J. Xu), and the National Natural Science Foundation of China (Grant No. 81703006 to T. Li).

\section{Authors' Contributions}

J. X. and X.Y. conceived the study; W.R., Z.L. and X.Y. wrote the manuscript; Z.L. and W.R. performed the transcriptome analysis with the help of S.H., Y.C., J.Z. and J.W.; Y.C., Y. W., Z. T. and T. L. conducted the clinical sample preparation and high-throughput sequencing. X. Y. and J. X. revised the manuscript. All authors reviewed the manuscript.

\section{Acknowledgements}

The Authors would like to thank all the medical and ancillary staff at the Cancer Center and the patients for consenting to participate. The Authors also thank Yun Shao and Yanhong Tai of the Department of Pathology for assistance with the preparation and assessment of formalin-fixed paraffin-embedded tumor samples, Gong-Jie Li of the Department of Radiology for assistance with radiological response evaluation and $\mathrm{TaO} \mathrm{Li}$ and $\mathrm{Xin}$ Pan for their helpful discussions. 


\section{References}

1 Brenner H, Kloor M and Pox CP: Colorectal cancer. Lancet Lond Engl 383: 1490-1502, 2014. PMID: 24225001. DOI: 10.1016/S0140-6736(13)61649-9

2 Van Cutsem E, Cervantes A, Nordlinger B, Arnold D and ESMO Guidelines Working Group: Metastatic colorectal cancer: ESMO Clinical Practice Guidelines for diagnosis, treatment and followup. Ann Oncol 25: iii1-9, 2014. PMID: 25190710. DOI: 10.1093/annonc/mdu260

3 Giampieri R, Scartozzi M, Prete MD, Maccaroni E, Bittoni A, Faloppi L, Bianconi M, Cecchini L and Cascinu S: Molecular biomarkers of resistance to anti-EGFR treatment in metastatic colorectal cancer, from classical to innovation. Crit Rev Oncol Hematol 88: 272-283, 2013. PMID: 23806981. DOI: 10.1016/ j.critrevonc.2013.05.008

4 Ciardiello $\mathrm{F}$ and Tortora G: EGFR Antagonists in Cancer Treatment. N Engl J Med 358: 1160-1174, 2008. PMID: 18337605. DOI: $10.1056 /$ NEJMra0707704

5 Jonker DJ, O'Callaghan CJ, Karapetis CS, Zalcberg JR, Tu D, Au H-J, Berry SR, Krahn M, Price T, Simes RJ, Tebbutt NC, van Hazel G, Wierzbicki R, Langer C and Moore MJ: Cetuximab for the treatment of colorectal cancer. N Engl J Med 357: 20402048, 2007. PMID: 18003960. DOI: 10.1056/NEJMoa071834

6 Karapetis CS, Khambata-Ford S, Jonker DJ, O'Callaghan CJ, Tu D, Tebbutt NC, Simes RJ, Chalchal H, Shapiro JD, Robitaille S, Price TJ, Shepherd L, Au HJ, Langer C, Moore MJ and Zalcberg JR: K-ras mutations and benefit from cetuximab in advanced colorectal cancer. N Engl J Med 359: 1757-1765, 2008. PMID: 18946061. DOI: 10.1056/NEJMoa0804385

7 Cunningham D, Humblet Y, Siena S, Khayat D, Bleiberg H, Santoro A, Bets D, Mueser M, Harstrick A, Verslype C, Chau I and Van Cutsem E: Cetuximab monotherapy and cetuximab plus irinotecan in irinotecan-refractory metastatic colorectal cancer. N Engl J Med 351: 337-345, 2004. PMID: 15269313. DOI: 10.1056/NEJMoa033025

8 Van Cutsem E, Köhne CH, Hitre E, Zaluski J, Chang Chien CR, Makhson A, D'Haens G, Pintér T, Lim R, Bodoky G, Roh JK, Folprecht G, Ruff P, Stroh C, Tejpar S, Schlichting M, Nippgen $\mathrm{J}$ and Rougier P: Cetuximab and chemotherapy as initial treatment for metastatic colorectal cancer. N Engl J Med 360: 1408-1417, 2009. PMID: 19339720. DOI: 10.1056/NEJM oa0805019

9 Van Cutsem E, Peeters M, Siena S, Humblet Y, Hendlisz A, Neyns B, Canon JL, Van Laethem JL, Maurel J, Richardson G, Wolf M and Amado RG: Open-label phase III trial of panitumumab plus best supportive care compared with best supportive care alone in patients with chemotherapy-refractory metastatic colorectal cancer. J Clin Oncol Off J Am Soc Clin Oncol 25: 1658-1664, 2007. PMID: 17470858. DOI: 10.1200/ JCO.2006.08.1620

10 Bokemeyer C, Bondarenko I, Makhson A, Hartmann JT, Aparicio J, Braud F de, Donea S, Ludwig H, Schuch G, Stroh C, Loos AH, Zubel A and Koralewski P: Fluorouracil, leucovorin, and oxaliplatin with and without cetuximab in the first-line treatment of metastatic colorectal cancer. J Clin Oncol 27: 663-671, 2009. PMID: 19114683. DOI: 10.1200/JCO.2008.20.8397

11 Lièvre A, Bachet JB, Le Corre D, Boige V, Landi B, Emile JF, Côté JF, Tomasic G, Penna C, Ducreux M, Rougier P, PenaultLlorca $\mathrm{F}$ and Laurent-Puig P: KRAS mutation status is predictive of response to cetuximab therapy in colorectal cancer.
Cancer Res 66: 3992-3995, 2006. PMID: 16618717. DOI: 10.1158/0008-5472.CAN-06-0191

12 Benvenuti S, Sartore-Bianchi A, Di Nicolantonio F, Zanon C, Moroni M, Veronese S, Siena S and Bardelli A: Oncogenic activation of the RAS/RAF signaling pathway impairs the response of metastatic colorectal cancers to anti-epidermal growth factor receptor antibody therapies. Cancer Res 67: 2643-2648, 2007. PMID: 17363584. DOI: 10.1158/0008-5472.CAN-06-4158

13 Amado RG, Wolf M, Peeters M, Van Cutsem E, Siena S, Freeman DJ, Juan T, Sikorski R, Suggs S, Radinsky R, Patterson SD and Chang DD: Wild-type KRAS is required for panitumumab efficacy in patients with metastatic colorectal cancer. J Clin Oncol 26: 1626-1634, 2008. PMID: 18316791. DOI: $10.1200 / J C O .2007 .14 .7116$

14 Loupakis F, Ruzzo A, Cremolini C, Vincenzi B, Salvatore L, Santini D, Masi G, Stasi I, Canestrari E, Rulli E, Floriani I, Bencardino K, Galluccio N, Catalano V, Tonini G, Magnani M, Fontanini G, Basolo F, Falcone A and Graziano F: KRAS codon 61,146 and BRAF mutations predict resistance to cetuximab plus irinotecan in KRAS codon 12 and 13 wild-type metastatic colorectal cancer. Br J Cancer 101: 715-721, 2009. PMID: 19603018. DOI: $10.1038 /$ sj.bjc 6605177

15 De Roock W, Claes B, Bernasconi D, De Schutter J, Biesmans B, Fountzilas G, Kalogeras KT, Kotoula V, Papamichael D, Laurent-Puig P, Penault-Llorca F, Rougier P, Vincenzi B, Santini D, Tonini G, Cappuzzo F, Frattini M, Molinari F, Saletti P, De Dosso S, Martini M, Bardelli A, Siena S, Sartore-Bianchi A, Tabernero J, Macarulla T, Di Fiore F, Gangloff AO, Ciardiello F, Pfeiffer P, Qvortrup C, Hansen TP, Van Cutsem E, Piessevaux $\mathrm{H}$, Lambrechts D, Delorenzi M and Tejpar S: Effects of KRAS, BRAF, NRAS, and PIK3CA mutations on the efficacy of cetuximab plus chemotherapy in chemotherapy-refractory metastatic colorectal cancer: a retrospective consortium analysis. Lancet Oncol 11: 753-762, 2010. PMID: 20619739. DOI: 10.1016/S1470-2045(10)70130-3

16 Di Nicolantonio F, Martini M, Molinari F, Sartore-Bianchi A, Arena S, Saletti P, De Dosso S, Mazzucchelli L, Frattini M, Siena $S$ and Bardelli A: Wild-type BRAF is required for response to panitumumab or cetuximab in metastatic colorectal cancer. J Clin Oncol 26: 5705-5712, 2008. PMID: 19001320. DOI: $10.1200 / J C O .2008 .18 .0786$

17 Bertotti A, Migliardi G, Galimi F, Sassi F, Torti D, Isella C, Corà D, Nicolantonio FD, Buscarino M, Petti C, Ribero D, Russolillo N, Muratore A, Massucco P, Pisacane A, Molinaro L, Valtorta E, Sartore-Bianchi A, Risio M, Capussotti L, Gambacorta M, Siena S, Medico E, Sapino A, Marsoni S, Comoglio PM, Bardelli A and Trusolino L: A molecularly annotated platform of patientderived xenografts ("Xenopatients") identifies HER2 as an Effective therapeutic target in cetuximab-resistant colorectal cancer. Cancer Discov 1: 508-523, 2011. PMID: 22586653. DOI: 10.1158/2159-8290.CD-11-0109

18 Sartore-Bianchi A, Martini M, Molinari F, Veronese S, Nichelatti M, Artale S, Di Nicolantonio F, Saletti P, De Dosso S, Mazzucchelli L, Frattini M, Siena S and Bardelli A: PIK3CA mutations in colorectal cancer are associated with clinical resistance to EGFRtargeted monoclonal antibodies. Cancer Res 69: 1851-1857, 2009. PMID: 19223544. DOI: 10.1158/0008-5472.CAN-08-2466

19 Misale S, Yaeger R, Hobor S, Scala E, Janakiraman M, Liska D, Valtorta E, Schiavo R, Buscarino M, Siravegna G, Bencardino K, Cercek A, Chen CT, Veronese S, Zanon C, Sartore-Bianchi 
A, Gambacorta M, Gallicchio M, Vakiani E, Boscaro V, Medico E, Weiser M, Siena S, Di Nicolantonio F, Solit D and Bardelli A: Emergence of KRAS mutations and acquired resistance to anti-EGFR therapy in colorectal cancer. Nature 486: 532-536, 2012. PMID: 22722830. DOI: 10.1038/nature 11156

20 Misale S, Arena S, Lamba S, Siravegna G, Lallo A, Hobor S, Russo M, Buscarino M, Lazzari L, Sartore-Bianchi A, Bencardino K, Amatu A, Lauricella C, Valtorta E, Siena S, Nicolantonio FD and Bardelli A: Blockade of EGFR and MEK intercepts heterogeneous mechanisms of acquired resistance to anti-EGFR therapies in colorectal cancer. Sci Transl Med 6: 224ra26-224ra26, 2014. PMID: 24553387. DOI: 10.1126/scitranslmed.3007947

21 Yonesaka K, Zejnullahu K, Okamoto I, Satoh T, Cappuzzo F, Souglakos J, Ercan D, Rogers A, Roncalli M, Takeda M, Fujisaka Y, Philips J, Shimizu T, Maenishi O, Cho Y, Sun J, Destro A, Taira K, Takeda K, Okabe T, Swanson J, Itoh H, Takada M, Lifshits E, Okuno K, Engelman JA, Shivdasani RA, Nishio K, Fukuoka M, Varella-Garcia M, Nakagawa K and Jänne PA: Activation of ERBB2 signaling causes resistance to the EGFR-directed therapeutic antibody cetuximab. Sci Transl Med 3: 99ra86, 2011. PMID: 21900593. DOI: 10.1126/scitranslmed.3002442

22 Bardelli A, Corso S, Bertotti A, Hobor S, Valtorta E, Siravegna G, Sartore-Bianchi A, Scala E, Cassingena A, Zecchin D, Apicella M, Migliardi G, Galimi F, Lauricella C, Zanon C, Perera T, Veronese S, Corti G, Amatu A, Gambacorta M, Diaz LA, Sausen M, Velculescu VE, Comoglio P, Trusolino L, Nicolantonio FD, Giordano S and Siena S: Amplification of the MET receptor drives resistance to anti-EGFR therapies in colorectal cancer. Cancer Discov 3: 658-673, 2013. PMID: 23729478. DOI: $10.1158 / 2159-8290 . C D-12-0558$

23 Montagut C, Dalmases A, Bellosillo B, Crespo M, Pairet S, Iglesias M, Salido M, Gallen M, Marsters S, Tsai SP, Minoche A, Seshagiri S, Serrano S, Himmelbauer H, Bellmunt J, Rovira A, Settleman J, Bosch F and Albanell J: Identification of a mutation in the extracellular domain of the Epidermal Growth Factor Receptor conferring cetuximab resistance in colorectal cancer. Nat Med 18: 221-223, 2012. PMID: 22270724. DOI: 10.1038/nm.2609

24 Eisenhauer EA, Therasse P, Bogaerts J, Schwartz LH, Sargent D, Ford R, Dancey J, Arbuck S, Gwyther S, Mooney M, Rubinstein L, Shankar L, Dodd L, Kaplan R, Lacombe D and Verweij J: New response evaluation criteria in solid tumours: revised RECIST guideline (version 1.1). Eur J Cancer Oxf Engl 1990 45: 228-247, 2009. PMID: 19097774. DOI: 10.1016/j.ejca.2008.10.026

25 Kim D, Pertea G, Trapnell C, Pimentel H, Kelley R and Salzberg SL: TopHat2: accurate alignment of transcriptomes in the presence of insertions, deletions and gene fusions. Genome Biol 14: R36, 2013. PMID: 23618408. DOI: 10.1186/gb-2013-14-4-r36

26 Anders S, Pyl PT and Huber W: HTSeq--a Python framework to work with high-throughput sequencing data. Bioinforma Oxf Engl 31: 166-169, 2015. PMID: 25260700. DOI: 10.1093/ bioinformatics/btu638

27 Harrow J, Frankish A, Gonzalez JM, Tapanari E, Diekhans M, Kokocinski F, Aken BL, Barrell D, Zadissa A, Searle S, Barnes I, Bignell A, Boychenko V, Hunt T, Kay M, Mukherjee G, Rajan J, Despacio-Reyes G, Saunders G, Steward C, Harte R, Lin M, Howald C, Tanzer A, Derrien T, Chrast J, Walters N, Balasubramanian S, Pei B, Tress M, Rodriguez JM, Ezkurdia I, van Baren J, Brent M, Haussler D, Kellis M, Valencia A, Reymond A, Gerstein M, Guigó R and Hubbard TJ: GENCODE: the reference human genome annotation for The ENCODE Project.
Genome Res 22: 1760-1774, 2012. PMID: 22955987. DOI: $10.1101 /$ gr.135350.111

28 Kozomara A and Griffiths-Jones S: miRBase: integrating microRNA annotation and deep-sequencing data. Nucleic Acids Res 39: D152-157, 2011. PMID: 21037258. DOI: 10.1093/nar/ gkq1027

29 Yoshihara K, Shahmoradgoli M, Martínez E, Vegesna R, Kim H, Torres-Garcia W, Treviño V, Shen H, Laird PW, Levine DA, Carter SL, Getz G, Stemke-Hale K, Mills GB and Verhaak RGW: Inferring tumour purity and stromal and immune cell admixture from expression data. Nat Commun 4: 2612, 2013. PMID: 24113773. DOI: $10.1038 /$ ncomms 3612

30 UniProt Consortium: UniProt: a hub for protein information. Nucleic Acids Res 43: D204-212, 2015. PMID: 25348405. DOI: 10.1093/nar/gku989

31 Dweep H, Gretz $\mathrm{N}$ and Sticht C: miRWalk database for miRNA-target interactions. Methods Mol Biol Clifton NJ 1182: 289-305, 2014. PMID: 25055920. DOI: 10.1007/978-14939-1062-5_25

32 Love MI, Huber W and Anders S: Moderated estimation of fold change and dispersion for RNA-seq data with DESeq2. Genome Biol 15: 550, 2014. PMID: 25516281. DOI: 10.1186/s13059014-0550-8

33 Huang DW, Sherman BT and Lempicki RA: Systematic and integrative analysis of large gene lists using DAVID bioinformatics resources. Nat Protoc 4: 44-57, 2009. PMID: 19131956. DOI: $10.1038 /$ nprot.2008.211

34 Huang DW, Sherman BT and Lempicki RA: Bioinformatics enrichment tools: paths toward the comprehensive functional analysis of large gene lists. Nucleic Acids Res 37: 1-13, 2009. PMID: 19033363. DOI: 10.1093/nar/gkn923

35 Rahman $M$ and Hasan MR: Cancer metabolism and drug resistance. Metabolites 5: 571-600, 2015. PMID: 26437434. DOI: $10.3390 /$ metabo5040571

36 Hanahan D and Weinberg RA: Hallmarks of cancer: The next generation. Cell 144: 646-674, 2011. PMID: 21376230. DOI: 10.1016/j.cell.2011.02.013

37 Toivola DM, Boor P, Alam C and Strnad P: Keratins in health and disease. Curr Opin Cell Biol 32: 73-81, 2015. PMID: 25599598. DOI: 10.1016/j.ceb.2014.12.008

38 Valentin MD, da Silva SD, Privat M, Alaoui-Jamali M and Bignon YJ: Molecular insights on basal-like breast cancer. Breast Cancer Res Treat 134: 21-30, 2012. PMID: 22234518. DOI: $10.1007 / \mathrm{s} 10549-011-1934-\mathrm{z}$

39 Cheung KJ, Gabrielson E, Werb Z and Ewald AJ: Collective invasion in breast cancer requires a conserved basal epithelial program. Cell 155: 1639-1651, 2013. PMID: 24332913. DOI: 10.1016/j.cell.2013.11.029

40 Schlessinger J: Cell signaling by receptor tyrosine kinases. Cell 103: 211-225, 2000.

41 Plaza-Menacho I, Morandi A, Robertson D, Pancholi S, Drury S, Dowsett M, Martin LA and Isacke CM: Targeting the receptor tyrosine kinase RET sensitizes breast cancer cells to tamoxifen treatment and reveals a role for RET in endocrine resistance. Oncogene 29: 4648-4657, 2010. PMID: 20531297. DOI: 10.1038/onc.2010.209

42 Jeselsohn R, Buchwalter G, De Angelis C, Brown M and Schiff $\mathrm{R}$ : ESR1 mutations - a mechanism for acquired endocrine resistance in breast cancer. Nat Rev Clin Oncol 12: 573-583, 2015. PMID: 26122181. DOI: 10.1038/nrclinonc.2015.117 
43 Nielsen KV, Ejlertsen B, Müller S, Møller S, Rasmussen BB, Balslev E, Lænkholm A-V, Christiansen P and Mouridsen HT: Amplification of ESR1 may predict resistance to adjuvant tamoxifen in postmenopausal patients with hormone receptor positive breast cancer. Breast Cancer Res Treat 127: 345-355, 2011. PMID: 20556506. DOI: 10.1007/s10549-010-0984-y

44 Della Corte CM, Bellevicine C, Vicidomini G, Vitagliano D, Malapelle U, Accardo M, Fabozzi A, Fiorelli A, Fasano M, Papaccio F, Martinelli E, Troiani T, Troncone G, Santini M, Bianco R, Ciardiello F and Morgillo F: SMO gene amplification and activation of the hedgehog pathway as novel mechanisms of resistance to anti-epidermal growth factor receptor drugs in human lung cancer. Clin Cancer Res 21: 4686-4697, 2015. PMID: 26124204. DOI: 10.1158/1078-0432.CCR-14-3319

45 Cheng H, Terai M, Kageyama K, Ozaki S, McCue PA, Sato T and Aplin AE: Paracrine Effect of NRG1 and HGF Drives resistance to MEK inhibitors in metastatic uveal melanoma. Cancer Res 75: 2737-2748, 2015. PMID: 25952648. DOI: 10.1158/0008-5472.CAN-15-0370

46 Tsang WP and Kwok TT: Riboregulator H19 induction of MDR1-associated drug resistance in human hepatocellular carcinoma cells. Oncogene 26: 4877-4881, 2007. PMID: 17297456. DOI: 10.1038/sj.onc.1210266

47 Li SP, Xu HX, Yu Y, He JD, Wang Z, Xu YJ, Wang CY, Zhang HM, Zhang RX, Zhang JJ, Yao Z and Shen ZY: LncRNA HULC enhances epithelial-mesenchymal transition to promote tumorigenesis and metastasis of hepatocellular carcinoma via the miR-200a-3p/ZEB1 signaling pathway. Oncotarget 7, 2016. PMID: 27285757. DOI: 10.18632/oncotarget.9883

48 Yang XJ, Huang CQ, Peng CW, Hou JX and Liu JY: Long noncoding RNA HULC promotes colorectal carcinoma progression through epigenetically repressing NKD2 expression. Gene 592, 2016. PMID: 27496341. DOI: 10.1016/j.gene.2016. 08.002

49 Akbari Moqadam F, Lange-Turenhout EA, Ariës IM, Pieters R and den Boer ML: MiR-125b, miR-100 and miR-99a co-regulate vincristine resistance in childhood acute lymphoblastic leukemia. Leuk Res 37: 1315-1321, 2013. PMID: 23915977. DOI: 10.1016/j.leukres.2013.06.027

50 Li W, Zhai L, Wang H, Liu C, Zhang J, Chen W and Wei Q: Downregulation of LncRNA GAS5 causes trastuzumab resistance in breast cancer. Oncotarget 7, 2016. PMID: 27034004. DOI: 10.18632 /oncotarget.8413

51 Zhang N, Yang GQ, Shao XM and Wei L: GAS5 modulated autophagy is a mechanism modulating cisplatin sensitivity in NSCLC cells. Eur Rev Med Pharmacol Sci 20: 2271-2277, 2016. PMID: 27338051

52 Zhang HH, Zhang ZY, Che CL, Mei YF and Shi YZ: Array analysis for potential biomarker of gemcitabine identification in non-small cell lung cancer cell lines. Int J Clin Exp Pathol 6: 1734-1746, 2013. PMID: 24040438.

53 Vychytilova-Faltejskova P, Pesta M, Radova L, Liska V, Daum O, Kala Z, Svoboda M, Kiss I and Slaby O: Genome-wide microRNA expression profiling in primary tumors and matched liver metastasis of patients with colorectal cancer. Cancer Genomics Proteomics 13: 311-316, 2016. PMID: 27365381.

54 Mitsuhashi K, Yamamoto I, Kurihara H, Kanno S, Ito M, Igarashi H, Ishigami K, Sukawa Y, Tachibana M, Takahashi H, Tokino T, Maruyama R, Suzuki H, Imai K, Shinomura Y, Yamamoto $\mathrm{H}$ and Nosho K: Analysis of the molecular features of rectal carcinoid tumors to identify new biomarkers that predict biological malignancy. Oncotarget 6: 22114-22125, 2015. PMID: 26090613. DOI: 10.18632/oncotarget.4294

55 Hur K, Toiyama Y, Schetter AJ, Okugawa Y, Harris CC, Boland $\mathrm{CR}$ and Goel A: Identification of a metastasis-specific MicroRNA signature in human colorectal cancer. J Natl Cancer Inst 107, 2015. PMID: 25663689. DOI: 10.1093/jnci/dju492

56 Salmena L, Poliseno L, Tay Y, Kats L and Pandolfi PP: A ceRNA hypothesis: the Rosetta Stone of a hidden RNA language? Cell 146: 353-358, 2011. PMID: 21802130. DOI: 10.1016/j.cell.2011.07.014

57 Poliseno L and Pandolfi PP: PTEN ceRNA networks in human cancer. Methods San Diego Calif 77-78: 41-50, 2015. PMID: 25644446. DOI: 10.1016/j.ymeth.2015.01.013

58 Keniry A, Oxley D, Monnier P, Kyba M, Dandolo L, Smits G and Reik W: The H19 lincRNA is a developmental reservoir of miR-675 that suppresses growth and Igf1r. Nat Cell Biol 14: 659-665, 2012. PMID: 22684254. DOI: $10.1038 / \mathrm{ncb} 2521$

59 Liang WC, Fu WM, Wong CW, Wang Y, Wang WM, Hu GX, Zhang L, Xiao LJ, Wan DCC, Zhang JF and Waye MMY: The lncRNA H19 promotes epithelial to mesenchymal transition by functioning as miRNA sponges in colorectal cancer. Oncotarget 6: 22513-22525, 2015. PMID: 26068968. DOI: 10.18632/ oncotarget.4154

60 Barsyte-Lovejoy D, Lau SK, Boutros PC, Khosravi F, Jurisica I, Andrulis IL, Tsao MS and Penn LZ: The c-Myc oncogene directly induces the $\mathrm{H} 19$ noncoding RNA by allele-specific binding to potentiate tumorigenesis. Cancer Res 66: 5330-5337, 2006. PMID: 16707459. DOI: 10.1158/0008-5472.CAN-06-0037

61 Tsang WP and Kwok TT: Riboregulator H19 induction of MDR1-associated drug resistance in human hepatocellular carcinoma cells. Oncogene 26: 4877-4881, 2007. PMID: 25790189. DOI: 10.1038/sj.onc.1210266

62 Yin D, He X, Zhang E, Kong R, De W and Zhang Z: Long noncoding RNA GAS5 affects cell proliferation and predicts a poor prognosis in patients with colorectal cancer. Med Oncol Northwood Lond Engl 31: 253, 2014. PMID: 25326054. DOI: 10.1007/s12032-014-0253-8

63 Dong S, Qu X, Li W, Zhong X, Li P, Yang S, Chen X, Shao M and Zhang L: The long non-coding RNA, GAS5, enhances gefitinib-induced cell death in innate EGFR tyrosine kinase inhibitor-resistant lung adenocarcinoma cells with wide-type EGFR via downregulation of the IGF-1R expression. J Hematol OncolJ Hematol Oncol 8: 43, 2015. PMID: 25925741. DOI: 10.1186/s 13045-015-0140-6

64 Overall CM and López-Otín C: Strategies for MMP inhibition in cancer: innovations for the post-trial era. Nat Rev Cancer 2: 657-672, 2002. PMID: 12209155. DOI: $10.1038 / \mathrm{nrc} 884$

65 Egeblad $M$ and Werb $Z$ : New functions for the matrix metalloproteinases in cancer progression. Nat Rev Cancer 2: 161-174, 2002. PMID: 11990853. DOI: $10.1038 / \mathrm{nrc} 745$

66 Coussens LM, Fingleton B and Matrisian LM: Matrix metalloproteinase inhibitors and cancer - trials and tribulations. Science 295: 2387-2392, 2002. PMID: 11923519. DOI: 10.1126/science. 1067100

67 Collado M, Blasco MA and Serrano M: Cellular Senescence in Cancer and Aging. Cell 130: 223-233, 2007. PMID: 17662938. DOI: $10.1016 /$ j.cell.2007.07.003

68 Rayess H, Wang MB and Srivatsan ES: Cellular senescence and tumor suppressor gene p16. Int J Cancer J Int Cancer 130: 17151725, 2012. PMID: 22025288. DOI: 10.1002/ijc. 27316 
69 Xing X, Cai W, Shi H, Wang Y, Li M, Jiao J and Chen M: The prognostic value of CDKN2A hypermethylation in colorectal cancer: a meta-analysis. Br J Cancer 108: 2542-2548, 2013. PMID: 23703248. DOI: 10.1038/bjc.2013.251

70 Hsieh JC, Kodjabachian L, Rebbert ML, Rattner A, Smallwood PM, Samos CH, Nusse R, Dawid IB and Nathans J: A new secreted protein that binds to Wnt proteins and inhibits their activites. Nature 398: 431-436, 1999. PMID: 10201374. DOI: $10.1038 / 18899$

71 Malinauskas T, Aricescu AR, Lu W, Siebold C and Jones EY: Modular mechanism of Wnt signaling inhibition by Wnt inhibitory factor 1. Nat Struct Mol Biol 18: 886-893, 2011. PMID: 21743455. DOI: 10.1038/nsmb.2081

72 Ko YB, Kim BR, Yoon K, Choi EK, Seo SH, Lee Y, Lee MA, Yang JB, Park MS and Rho SB: WIF1 can effectively coregulate pro-apoptotic activity through the combination with DKK1. Cell Signal 26: 2562-2572, 2014. PMID: 25086206. DOI: $10.1016 /$ j.cellsig.2014.07.026
73 Morandi A, Martin LA, Gao Q, Pancholi S, Mackay A, Robertson D, Zvelebil M, Dowsett M, Plaza-Menacho I and Isacke CM: GDNF-RET signaling in ER-positive breast cancers is a key determinant of response and resistance to aromatase inhibitors. Cancer Res 73: 3783-3795, 2013. PMID: 23650283. DOI: $10.1158 / 0008-5472 . C A N-12-4265$

Received February 17, 2019

Revised April 5, 2019

Accepted April 8, 2019 